\title{
APPLICATION OF THE MULTI-POTENTIAL GEOPHYSICAL TECHNIQUES FOR GROUNDWATER EVALUATION IN A PART OF CENTRAL SINAI PENINSULA, EGYPT
}

\section{Hussain Tawfik EL-BADRAWY ${ }^{1)}$, Sultan Awad Sultan ARAFFA ${ }^{2)}$ * and Ahmed Fathy GABR GABR ${ }^{3)}$}

\author{
1) Faculty of Science, Kafrelshiekh University, Kafrelshiekh, Egypt \\ 2) National Research Institute of Astronomy and Geophysics (NRIAG), Helwan, Cairo, Egypt \\ 3) National Water Research Center (NWRC), Research Institute for Ground Water (RIGW), Cairo, Egypt
}

*Corresponding author's e-mail: sultan_awad@yahoo.com

\section{ARTICLE INFO}

Article history:

Received 7 December 2020

Accepted 25 January 2021

Available online 11 February 2021

\section{Keywords:}

Geoelectrical-gravity-magnetic-crustal modeling

Central Sinai

\begin{abstract}
This study highlights the groundwater evaluation of the Nubian sandstone aquifers regarding assessing the main structural elements, trends, and depth to the basement rocks that control the groundwater aquifers in Egypt's central Sinai area.

Gravity and magnetic data were analyzed using different techniques, such as wavenumber filtering, least-squares separation techniques, and tilt derivatives. Euler deconvolution with different structural indexes (SI), power spectrum analyses, 3-D crustal modeling. The deep-seated structures affecting the study area, and the basement depth, which range between 1170 and $4590 \mathrm{~m}$., have been utilized.

The main structural trends affecting the study area were delineated to control the groundwater aquifer's regional geometry. Moreover, it was found that the NorthWest-SouthEast trend direction - Suez Gulf trend - was caused by primary shear, and the NorthEast-SouthWest trend direction Aqaba Gulf trend - was caused by the secondary shear. The direction of each trend's lateral movement was to the right and the left, respectively.

Meanwhile, the geoelectrical resistivity measurements were also utilized to determine the ground water-bearing formations using eighteen deep vertical electrical soundings (VES) stations. The results revealed the depth to the uppermost part of the Nubian sandstone aquifer ranging between 598 and $1106 \mathrm{~m}$; the combination of the depth to the uppermost part of the Nubian aquifer, the depth of the basement relief map revealed that the aquifer thickness varies from 430 to $3750 \mathrm{~m}$, and the resistivity values ranging between 22 and $214 \Omega . \mathrm{m}$.
\end{abstract}

\section{INTRODUCTION}

The area of study lies in the central Sinai Peninsula, Egypt, between Latitude of $29^{\circ} 25^{`} \mathrm{~N}$ and $29^{\circ} 51^{\prime} \mathrm{N}$ and Longitude of $33^{\circ} 05^{\prime} \mathrm{E}$ and $34^{\circ} 45^{\prime} \mathrm{E}$ (Fig. 1a). Different geomorphological features characterize it, such as high ridges, such as Gebels EL- Raha, EL-Risha, EL-Gushiya, Matulla, Samra, Nukhul, Hazbaa, Himeiyir Um Rinna, and EL-Tih exist. The study area contains several groundwater resources of great value that can grant future progression projects (Ahmed et al., 2014; Sultan et al., 2013). This study aims to recapitulate, investigate the deep-seated structures that dissect the investigated area, and identify the basement rocks' depths and relief. Also, determine the groundwater occurrences in the study area. Many authors studied this area by using Potential methods, including geoelectrical resistivity. Gravity and magnetic methods to investigate the deepseated structures and groundwater occurrence (Mckenzie et al., 1970; Ben-Menahem and Aboodi, 1971; Bartov et al., 1980; EL-Badrawy et al., 2003; ElAwadi, 2010). Moreover, the geoelectrical resistivity method has been applied to identify the Nubian sandstone aquifer (Sultan et al., 2009; Araffa, 2013; Araffa et al., 2015). The study area represents an integral region of Sinai, where it occupies the central region. People who live in central Sinai (Bedouins) suffer from a scarcity of water supply. For this reason, the current study was applied for delineating groundwater aquifer, especially the deep Nubian sandstone one, which is freshwater quality using deep VES stations with $\mathrm{AB} / 2$ up to $3000 \mathrm{~m}$. The thickness of this aquifer is determined through the interpretation of magnetic and geoelectrical resistivity data. Most previous works are interested in the shallow aquifer, which is more or less of brackish water using geophysical techniques.

\section{GEOLOGIC SETTING}

Geomorphologically, the study area consists mainly of the El-Egma plateau, which is considered to be the main watershed area in central Sinai, where many lines of drainage that makeup Wadi El Arish's intake dissect its surface (Ghoubachi, 2013). It is composed mostly of northward slightly plunging strata of limestone and massive chalk of Lower Eocene and 
Upper Cretaceous, respectively. Various hilly and mountainous terrains dissect the eastern sector of El gma plateau to the northwest. The East portion of this unit is $1000 \mathrm{~m}$ high and reduced to about 700 to the north; this is formed by sedimentary mountains and hills (El Hinnawi and Samy, 1995).

Tectonically, the central Sinai lies in a stable shelf-zone to the north of the southern basement complex. Several minor normal faults characterized it as $\mathrm{N}-\mathrm{S}$ to $\mathrm{NNE}-\mathrm{SSW}$ related to the Aqaba Gulf trend, NorthWest - SouthEast referred to the Suez Gulf trend, and East-West referred to Mediterranean Sea trend (Shata, 1956). Ragabet El Naam Fault lies at the border between stable and transition zone with trending East-West direction with a movement of $2.5 \mathrm{~km}$ (Steinitz et al., 1978).

According to UNESCO's surface geological map in 2005 (Fig. 1b; UNESCO Cairo Office, 2005), the found exposed rock units are represented by Wadi and Hamada deposits, which belong to the Quaternary age. Al-Kuntilla, Darat, Egma, Esna belong to Pliocene, Lower-Middle Eocene, Lower Eocene, and Paleocene ages, respectively. While, Sudr, Duwi, Matulla, Wata, Galala formations belong to the Cretaceous age.

The stratigraphic section in the study area shows a range of sedimentary sequence that starts with the early cretaceous and ends up with Holocene. The Malha, Galala, Wata, Matulla, Duwi, Sudr formations represent the Cretaceous age. While Esna, Egma, and Wadi deposits, belong to Paleocene, Lower Eocene, Holocene, respectively (Fig. 1d).

\section{GEOPHYSICAL METHODS}

Bouguer anomaly and total intensity magnetic data are used to investigate the deep-seated structure trends affecting the studied area, which control the groundwater's regional geometry, the basement relief, and depths were also delineated. Moreover, geoelectrical resistivity measurements were utilized to recognize the geoelectrical units and detect groundwater bearing formation.

\subsection{GRAVITY MEASUREMENTS}

Gravity field measurements have been determined all over 224 land stations, $2-3 \mathrm{~km}$ apart in flat and terrain areas, using CG-3 gravimeter. Stations were settled in a grid-like design to include the entire area at $0.01 \mathrm{mGal}$ gravimeter sensitivity. Drift, Free- air, Tide, Latitude, Bouguer, and Topographic corrections are examples of (Oasis Montaj, 2015) software's gravity corrections to correct the measured gravity values. Consequently, it was possible to generate the Bouguer anomaly map of the study area (Fig. 2a).

The map exhibited a high-gravity anomaly $(+32.7 \mathrm{mGal})$ in the western, southeastern, and northeastern parts of the map; however, it reveals a low-gravity anomaly $(-93.7 \mathrm{mGal})$ in the eastern, southern, northern, and central portions.
Closed anomalies of high- and low-gravity were also shown in both southern and central parts. They were interpreted to be an outcome of the basement structures and inside the sedimentary layers. Meanwhile, another type of anomalies, linear anomalies, was found to have diverse directions like NE-SW trend and NorthWest-SouthEast trend, corresponding to the Aqaba Gulf and corresponding to the Suez Gulf.

\subsection{MAGNETIC MEASUREMENTS}

Two hundred and twenty-one land magnetic stations were used to measure the magnetic data through Envi-mag proton magnetometers of sensitivity $1 \mathrm{nT}$. These measurements required two devices: one used for surveying, and the other is used as a base station to estimate the diurnal variation in the magnetic field of the earth.

The correction of the observed magnetic data has also been done, and the total intensity magnetic map (TMI) was constructed with a magnetic field varying from $41552.7 \mathrm{nT}$ to $43013.1 \mathrm{nT}$ (Fig. 3a; Oasis Montaj, 2015 software). Parameters of the magnetic field where this site exists (inclination $\mathrm{I}=43.44^{\circ}$, declination $\mathrm{D}=2.78^{\circ}$, and the magnetic field strength $=43038.47 \mathrm{nT}$ ) were used to produce the RTP map (Fig. 3b), which shows that the magnetic field varies from $41428 \mathrm{nT}$ to $43401.7 \mathrm{nT}$.

\subsection{GEOELECTRICAL MEASUREMENTS}

Eighteen deep VES stations represented the geoelectrical resistivity survey have been conducted using the Syscal R2 device with the Schlumberger configuration of $\mathrm{AB} / 2$ spacing ranging between $\mathrm{AB} / 2=5 \mathrm{~m}$ and $\mathrm{AB} / 2=3000 \mathrm{~m}$ (see Fig. 1c for location). VES stations numbers 7 and 15 were measured near the boreholes: Al-Temid-2 (RIGW, 2017) and JICA-2 (JICA, 1992), respectively. The VES stations were quantitatively interpreted through two steps; in the first one, a two-layer master curve technique was used to estimate an initial earth model for each VES. After that, the (IPI2WIN-1D, 2003) edition was used with the initial earth model to determine the actual one-dimensional model depths and resistivities for each VES curve (Figs. 6a, b).

\section{RESULTS}

\subsection{GRAVITY RESULTS}

Filtering procedures were implemented in the investigated area's measured gravity data to separate different wavelengths' anomalies. High-and Low-pass filters were used to separate the local anomalies of near-surface sources from the regional anomalies related to profound sources, which have $0.0596 \mathrm{cycle} / \mathrm{km}$ cut-off wavenumber that was obtained from the radially averaged power spectrum (RAPS) (Fig. 2b). 


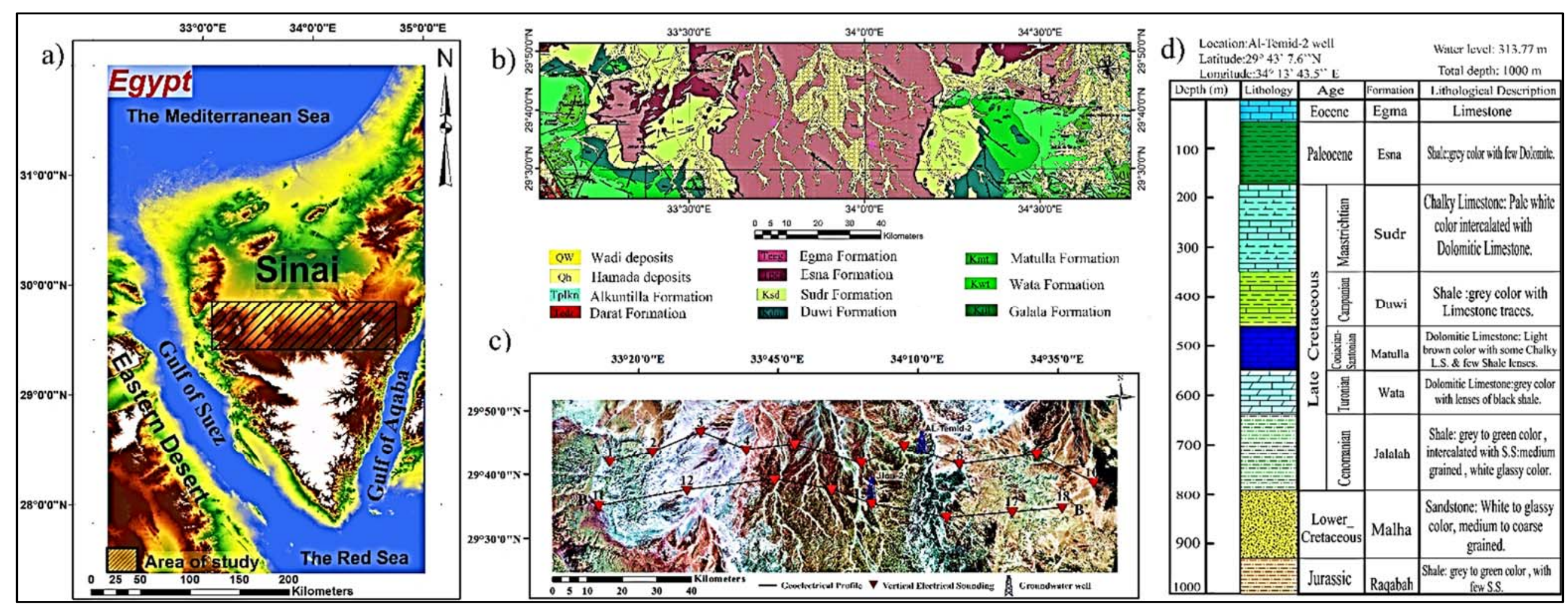

Fig. 1 a) Map where the investigated area lies, b) Geological Map of the study area (Executed by UNESCO, Cairo Office, 2005), c) Vertical Electrical Sounding (VES) distribution in the investigated area, d) Lithostratigraphic sequence of Al-Temid well No. 2 (after RIGW, 2017). 

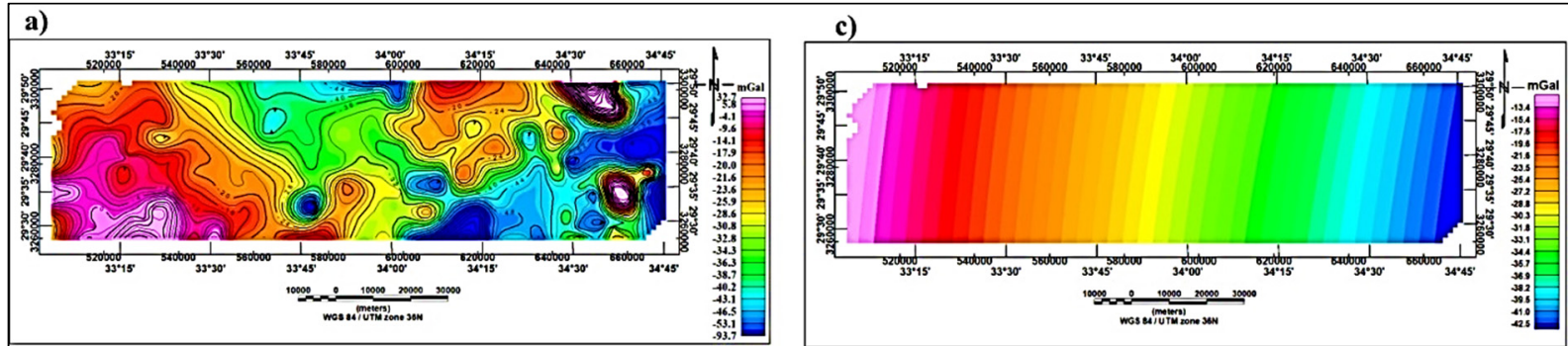

b)

d)

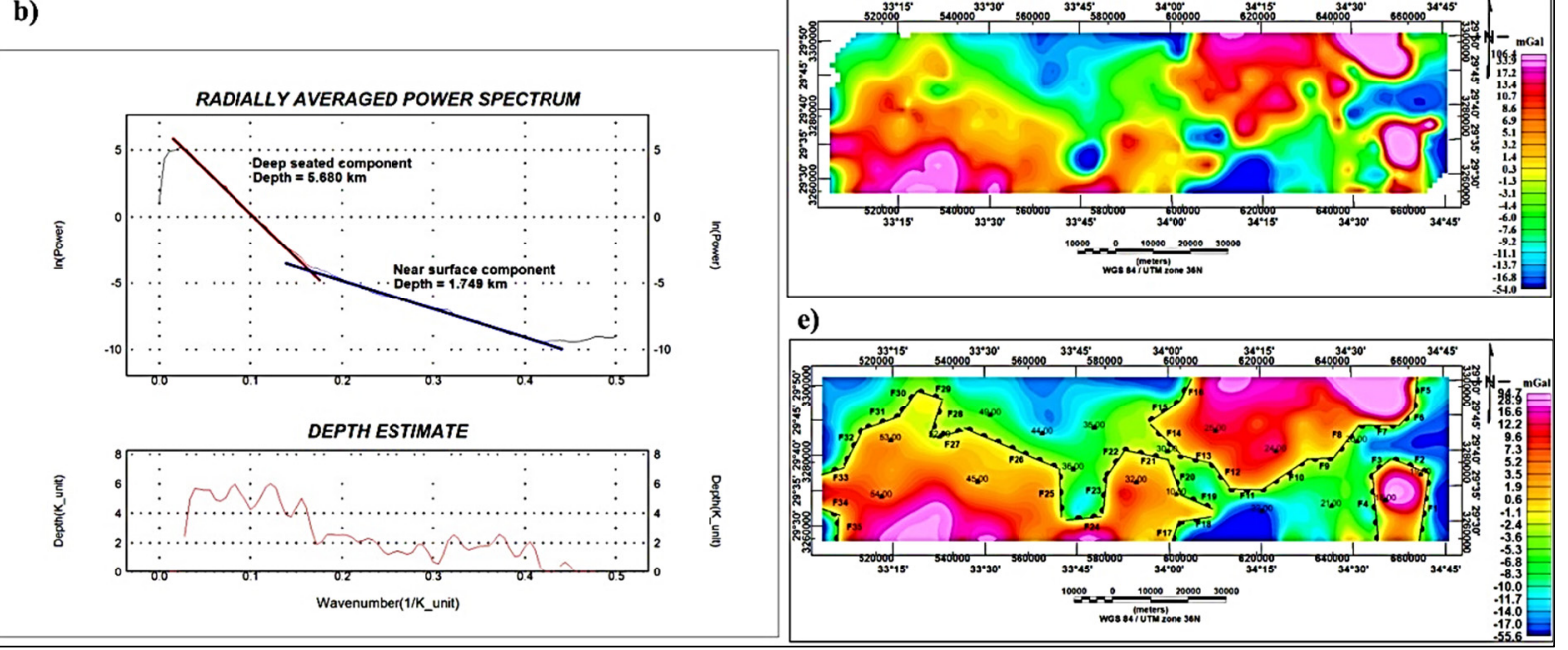

Fig. 2 a) Bouguer anomaly map in the study area C.I=2 mGal, b) 2-D radially averaged power spectrum of the gravity data, c) Regional gravity anomaly map with a cut wave number of $0.0596 \mathrm{~km}, \mathrm{~d}$ ) Residual gravity anomaly map with a cut wave number of $0.0596 \mathrm{~km}, \mathrm{e}$ ) residual gravity anomaly map at the third order.

Generally, the regional gravity map represents several significant anomalies of various extensions, orientations, and forms that are constituent with the main density variations and are viewed to have a depth more significant than the overall exploration interest (Fig. 2c). On the other hand, the residual map, shown in (Fig. 2d), illustrated some smaller anomalies that are arranged with the NE-SW (Aqaba Gulf) and NW-SE (Suez Gulf) directions, which are prevalent in the investigated area. The least-squares technique was applied to estimate the residual component of the potential field data. This technique's resulting maps help choose the particular anomalies to be analyzed (Nettleton, 1976).

The correlation coefficients between the different consecutive residual gravity maps were estimated to define the regional surface's best order to be utilized. The results of correlation coefficients between the different consecutive residual gravity maps are $r_{12}=0.769836369, r_{23}=0.791120612$, $\mathrm{r}_{34}=0.999931914$ and $\mathrm{r}_{45}=0.999931581$. This criterion indicates that the investigated area's best residual field is the third-order surface (Fig. 2e).

The Bouguer's critical features and the resulting residual-gravity-anomaly maps (Figs. 2a, e) in the investigated area were resumed as follows:
1. The residual map contains several small anomalies with NorthEast-SouthWest and NorthWest-SouthEast that are consistent with the significant pattern of the Bouguer-anomaly map's faults, indicating that the permanent fault pattern started from the deep to the near-surface depths.

2. Small circular closed anomalies with different shapes are scattered all over the study area, especially in the central, eastern, western, and southern portions, indicating that it may be plugged. Also, some elongated anomalies are located in the western and northern portions, which suggested that these structures may be dikes.

3. Basin structures with magnitudes $(-55.6 \mathrm{mGal})$ are mostly located in the eastern, northern, and southern portions; however, the denser basement rocks' uplift with magnitude $(+94.7 \mathrm{mGal})$ is primarily located in the western, northeastern, and southeastern portions.

4. Linear short belts, such as faults impacting the basement complex and the sedimentary layers, in a direction similar to linear belts were deduced from the Bouguer-gravity map (NorthEastSouthWest, and NorthWest-SouthEast trends). 

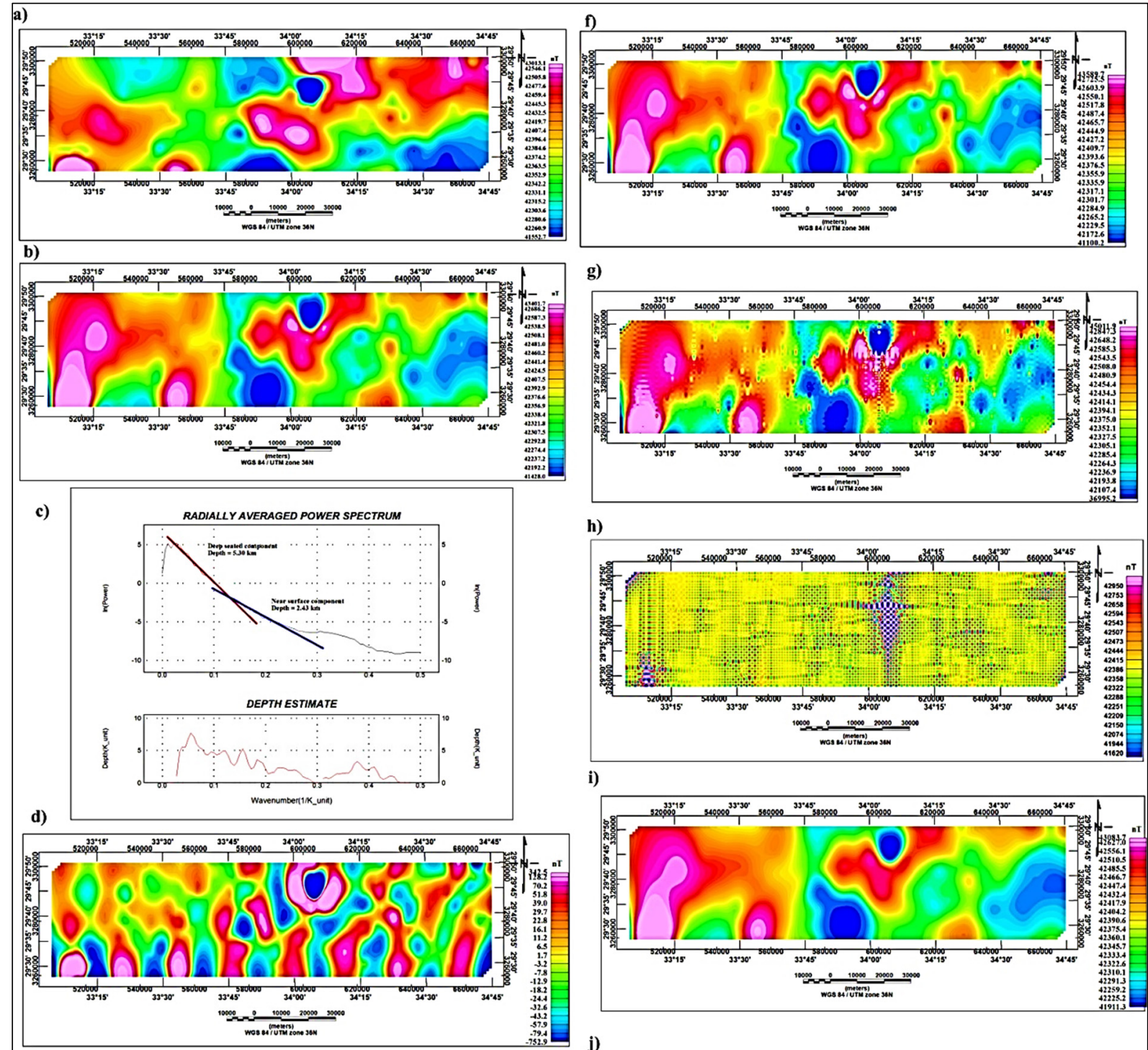

i)
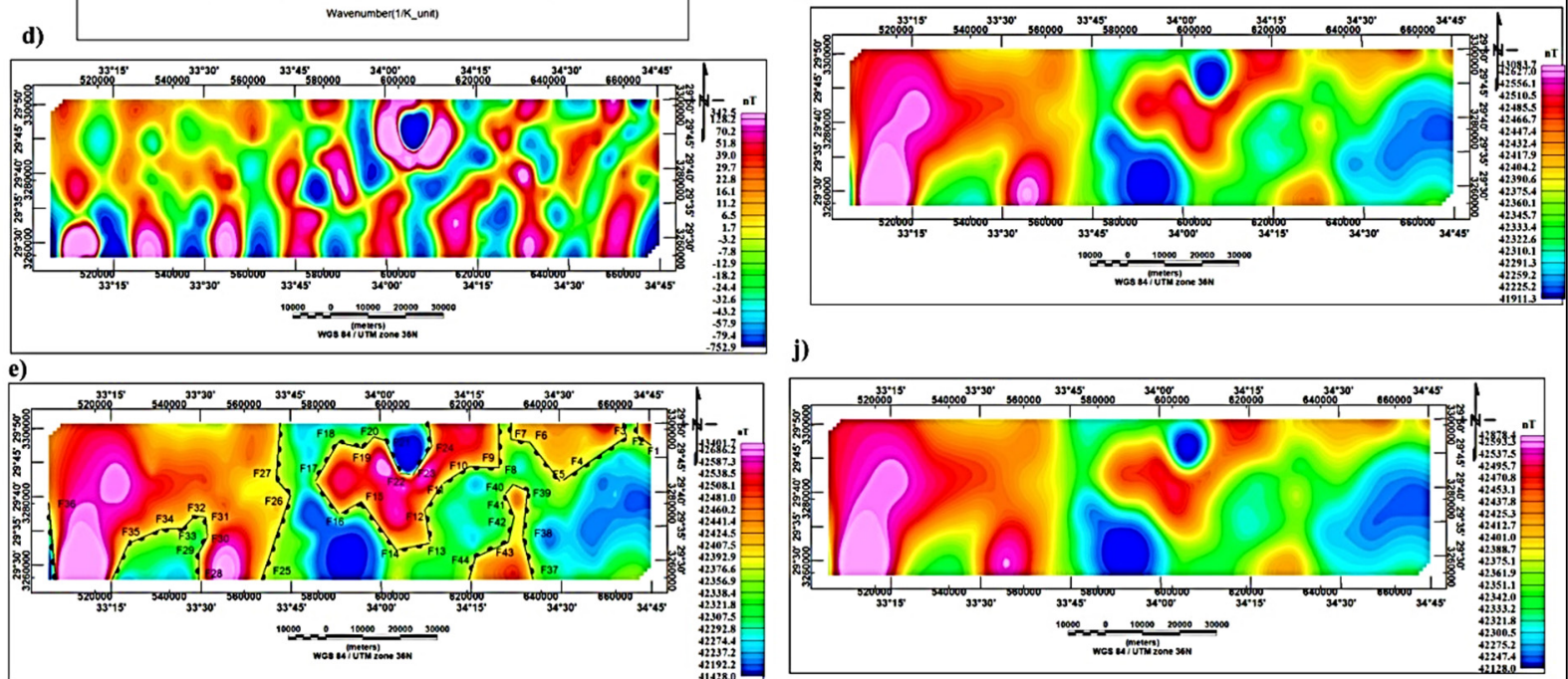

j)

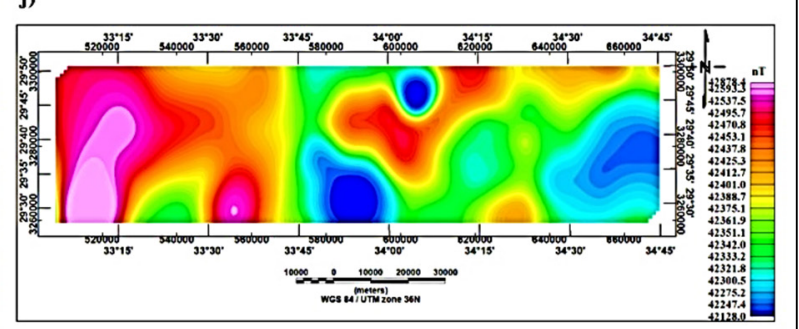

Fig. 3 a). Total intensity magnetic map, b) Total intensity magnetic map reduced to the magnetic pole (RTP), c) 2-D radially averaged power spectrum of the RTP magnetic data, d) Residual RTP magnetic map by using a high-pass filter with a Cut wave number of $0.049 \mathrm{~km}^{-1}$, e) Fault elements dissecting the study area, and Downward continuation of (RTP) magnetic anomaly maps at depths, f) 500, g) 1500, h) 3000, and Upward continuation of (RTP) magnetic anomaly maps at depths. i) 1500 , j) $3000 \mathrm{~m}$, respectively.

The RAPS of the gravity data was calculated depending on depth defining method that calculates power spectra, which are in two dimensions, from gridded gravity measurements for depth investigation established by (Spector and Grant, 1970). Depth calculations done on the parts illustrates that the mean depth measurements are $5.680 \mathrm{~km}$ for deep and $1.749 \mathrm{~km}$ for shallow depths of gravity sources, respectively (Fig. 2b). Estimating the source locations and their depths of 2-D gravity causative sources from profile data could be automatically interpreted using the Euler deconvolution technique. It calculates the first-order derivative, which becomes the most frequently used (Thompson, 1982; Reid et al., 1990; Ugalde and Morris, 2010; Zhou et al., 2016). 


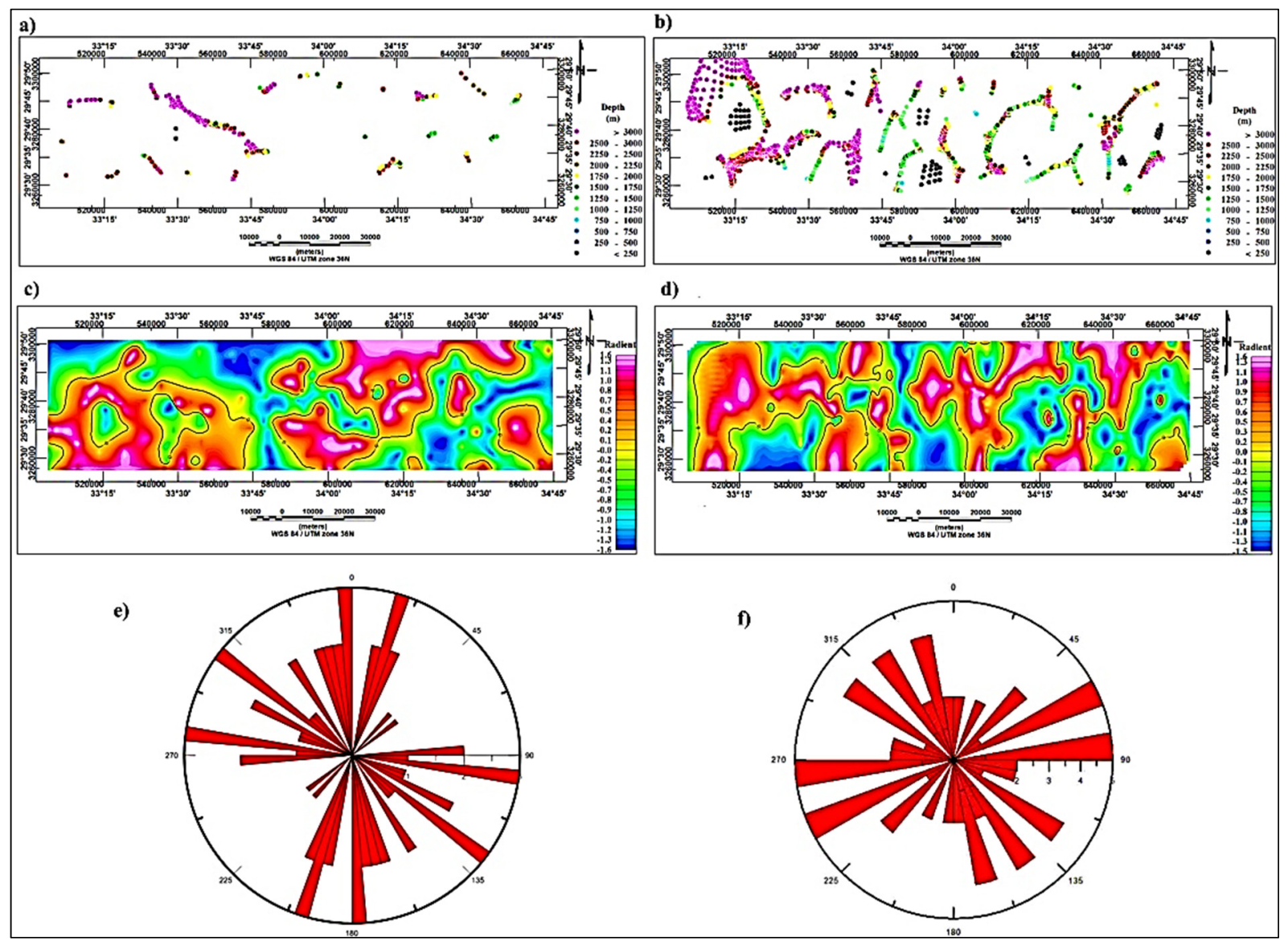

Fig. 4 a) and b) Euler solutions using structural index $=0$ on gravity and RTP map, c) and d) Tilt derivative of gravity and magnetic, e) and f) Major trends of faults dissecting the study area of gravity and magnetic.

We are applying Euler's solutions to the gravity maps deploying the Zero structure index to plot the location, depth, and trend of the structures, which both are deep-seated or near-surface (contacts and faults). The depth range of basement rocks is from 1.25 to $3 \mathrm{~km}$, with remarkable gathering and linear segment trending in NE-SW (Fig. 4a), directions corresponding to the Aqaba Gulf and NorthWest-SouthEast directions corresponding to the Suez Gulf (Fig. 4e). On the other hand, Euler's solutions for this map could not give consistent depth values for the northeastern, southwestern, and eastern portions of the area, which matches the basement uplift. An insignificant gradient of the anomalies might cause this. Consequently, for this zone, the depth which was determined from the modeling is measured.

\subsection{MAGNETIC RESULTS}

The low- and high-pass filters, which were applied to the RTP, calculated the regional and residual components, respectively, with 0.049 cycle $/ \mathrm{km}$ cut-off wave numbers attained from the RAPS. Unlike the regional magnetic map, the residual magnetic map represents shallow sources' anomalies (Fig. 3d).

Many consecutive downward continuation filters were applied to RTP data using grid spacing 500, 1500, and $3000 \mathrm{~m}$ (Figs. 3f-h). On these maps, the anomalies started to split when reaching the depth of $1500 \mathrm{~m}$, and this probably shows that the uppermost part of the basement source lies near this depth. At depth $3000 \mathrm{~m}$, the splitting of the anomalies was increased, indicating that the basement source base lies near this depth. The same grid spacing was used to carry out the upward continuation to give information about the modification in anomaly character while raising the observation level to source distance. Careful examination of the upward continuation maps (Figs. 3i, j) shows unlimited resemblance in their character with RTP magnetic map. It may designate that majority of irregularities originate from a profound source.

The RAPS of the magnetic field data was applied to estimate the depth of regional and residual components. Depth calculations done on the parts illustrate that the mean depth measurements are 5.300 $\mathrm{km}$ for deep and $2.430 \mathrm{~km}$ for shallow depths of magnetic sources, respectively (Fig. 3c). 


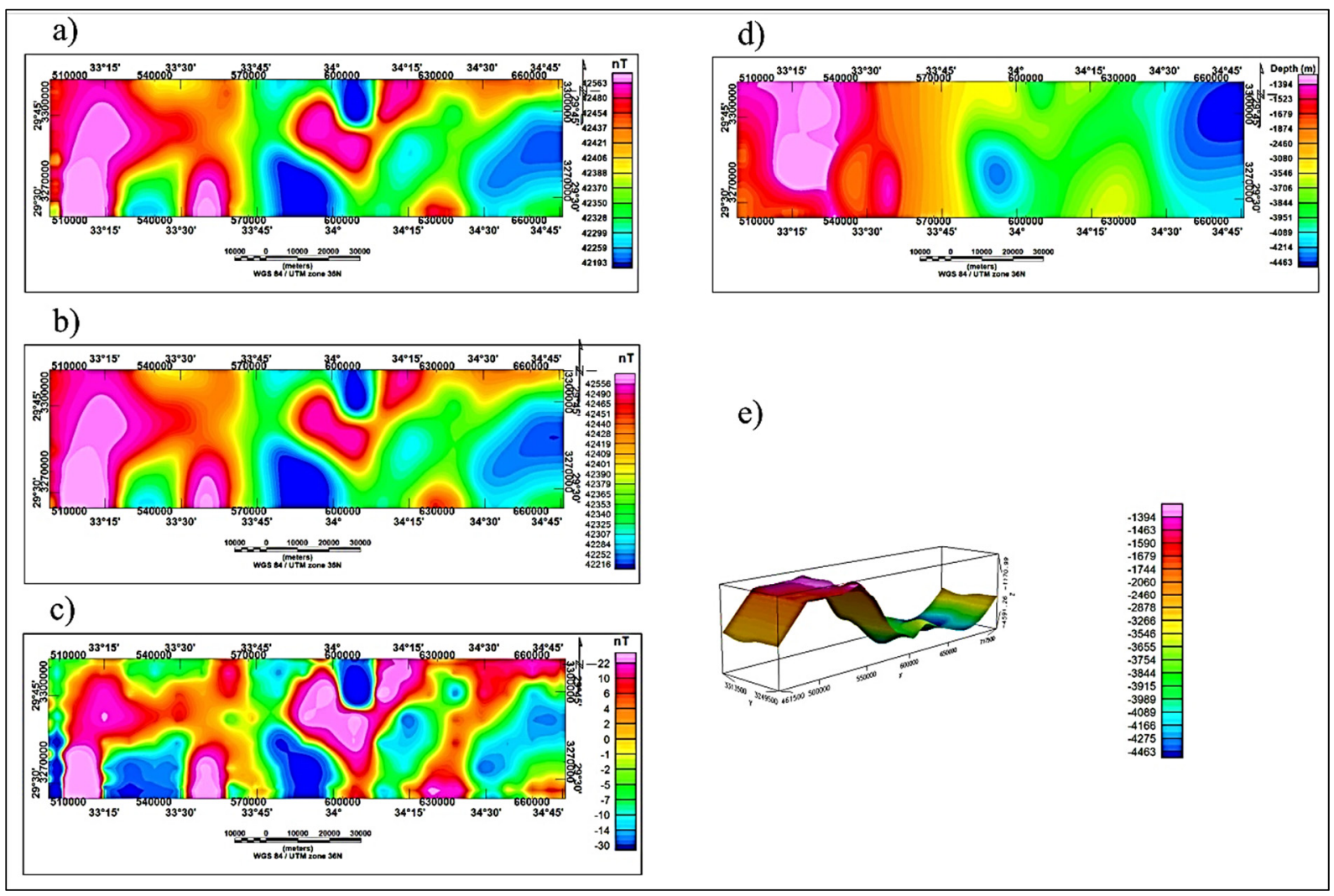

Fig. 5 3-D Magnetic Modeling, a) Observed magnetic map RTP map after applying smoothing, b) Calculated map resulted from GM-SYS-3D software, c) Error map represents the difference between observed and calculated maps, d) represents depth relief map from GM-SYS 3D software, e) Represents 3-view of basement relief map.

The Euler depth deconvolution method was applied to the RTP map using a structural index equal to zero to map the location, depth, and trends of structures (contacts and step). Euler solutions for the RTP map (Fig. 4b) shows that the depth of the studied structure ranges from 1.00 to $3 \mathrm{~km}$; it takes different directions: NE-SW trend, which is corresponding to Aqaba Gulf, and NorthWest-SouthEast trend, which is corresponding to the Suez Gulf as shown in (Figs. 3e, and 4f).

Finally, as an effective edge detection technique, tilt derivative (TDR) has been applied to both the Bouguer anomaly map and the RTP map (Verduzco et al., 2004) to give a conception of the edges of the possible uplifted basement blocks as at the northeastern part of the study area. The possible basins' edges are at the northern region of the investigated area, concerning zero contour line (contour lines of the tilt angle with zero value) (Figs. 4c, and 4.d). Both the raised basement blocks and the basins have been controlled by many faults that match the edges of the complex blocks and the sedimentary basins; accordingly, the TDR maps show that several faults dissect the area under investigation takes different trends; NE-SW trend which has the same trend of Aqaba Gulf and NW-SE trend have the same trend of Suez Gulf.
The 3-D magnetic inversion was carried out on magnetic data using (GMSYS-3D, 2015) software. The basement surface depth could be found in the (Parker, 1972) algorithm wavenumber domain. In this work, the susceptibility of 7750 micro CGS (Sultan et al., 2009) was used for the basement complex. The observed and calculated maps are compatible, and the error ratio is minor (Figs. 5a, b, c).

After 3-D modeling, basement relief, and 3-D view map (Figs. 5d, e) led us to know the basement depth of the investigated area. The depth to reach the uppermost part of the crystalline rocks has a value between $1170 \mathrm{~m}$ in the western portion of the study area and about $4590 \mathrm{~m}$ in the eastern portion of the investigated area.

\subsection{GEOELECTRICAL RESISTIVITY RESULTS}

The quantitative interpretation of data related to each VES indicates that eight geoelectrical units can represent most VES stations. The interpreted vertical electrical soundings were utilized to construct two geoelectrical cross-sections, A-A ' and B-B', each of which comprises eight geoelectrical units, as shown in (Figs. 6c, d) respectively.

The first geoelectrical unit measures 2 to $29 \mathrm{~m}$ thickness and 29 to $260 \Omega . m$ resistivity, represents the Quaternary Wadi deposits. 


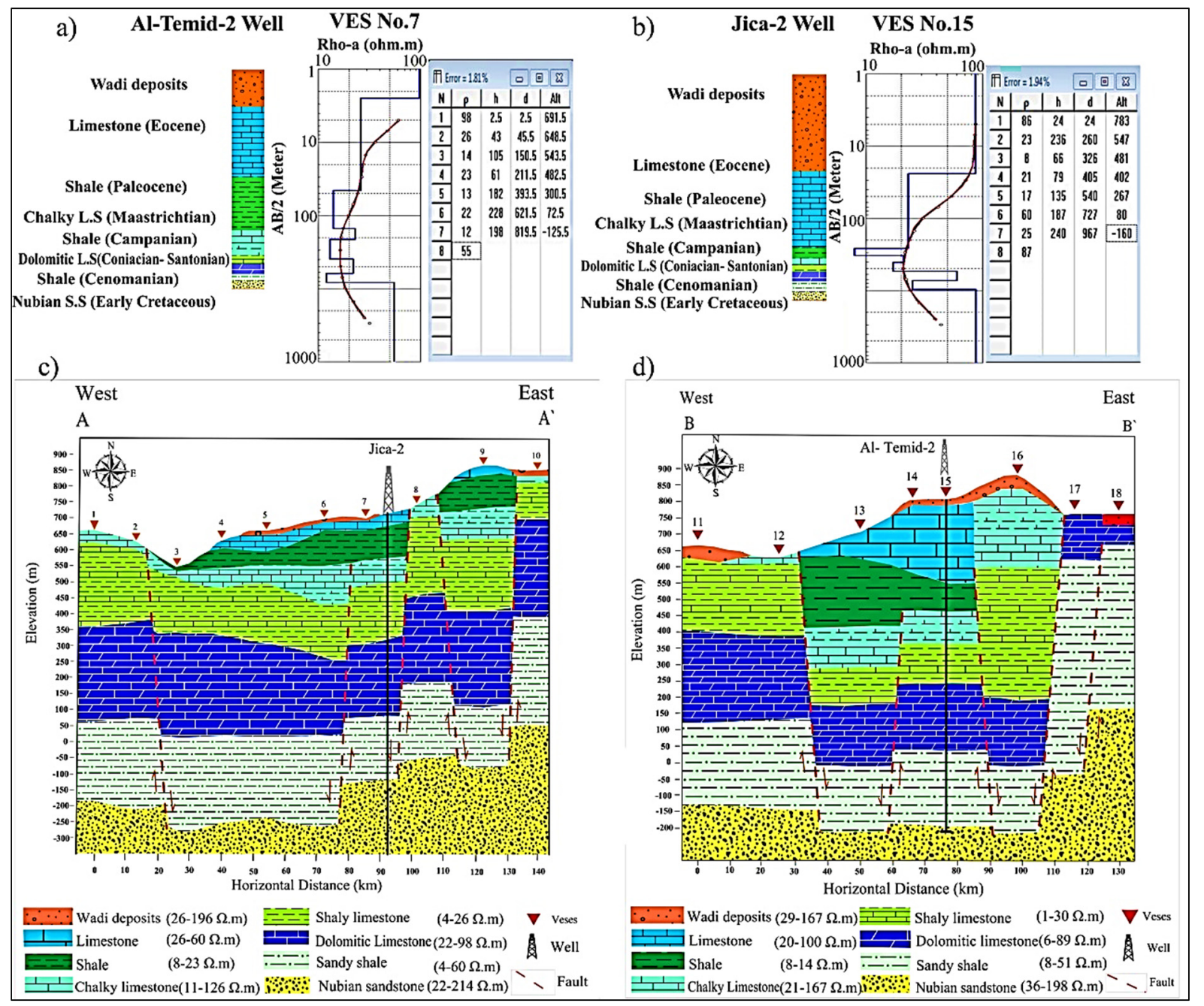

Fig. 6 Resistivity models for VESes 7 and 15 and its correlation and the geological logs acquired from the boreholes, a) Al- Temid -2, and b) JICA 2, and c) 1D Geoelectrical cross-section along profile A-A'. d) $1 \mathrm{D}$ Geoelectrical cross-section along profile B-B'. respectively.

- The second one measures 25-236 m thickness and 20 - $100 \Omega$.m resistivity representing limestone of Egma-Formation of the Eocene age.

- $\quad$ The third unit measures 2.7 - 229 m thickness and 8 - $23 \Omega . m$ resistivity, representing the shale of Esna-Formation of Paleocene age.

- The fourth one was considered as chalky limestone of Sudr-Formation of Maastrichtian age. It measures $4-248 \mathrm{~m}$ thickness and 11$167 \Omega . m$ resistivity.

- The fifth one was considered as shale of Campanian Duwi-Formation, and it measures a thickness ranging between 133 and $400 \mathrm{~m}$ and a relatively low resistivity ranging between 1 and

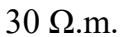

- The sixth one consists of Dolomitic limestone with few shales that can be interpreted as Matulla and Wata formations of the Turonian age. This unit's thickness ranges from 80 to $322 \mathrm{~m}$, and the true resistivity of it varied from 6 to $98 \Omega$.m.
- The seventh one was mainly consisted of shale with some sand intercalation of the Galala Formation of the Cenomanian age. It measures a thickness ranging between 186 and $634 \mathrm{~m}$ and resistivity ranging between 4 and $60 \Omega . \mathrm{m}$.

- The last geoelectrical unit performs the principal aquifer in the area under investigation, where the uppermost part of this unit was identified at a depth ranging between 598 and $1106 \mathrm{~m}$ and a wide resistivity range from $22-214 \Omega . \mathrm{m}$. This geoelectrical unit consists of Malha-Formation sandstone (Nubian sandstone), which belongs to Lower Cretaceous.

\section{DISCUSSION}

The results of integrated interpretation of different geophysical techniques are compatible where the major fault trends controlling the groundwater aquifer take directions: NE-SW, equivalent to the Aqaba Gulf trend, and NorthWest-SouthEast, equivalent to the Suez Gulf trend, as deduced from 
Euler deconvolution analysis, and the TDR technique applied to RTP map and the Bouguer anomaly map at third order using a cut-off frequency $0.0596 \mathrm{~km}^{-1}$.

Based on the above results, it is clear that the fault trends obtained from magnetic data resemble those found in the residual gravity anomaly map and TDR maps. It was possible to spot similarities between the radially-averaged power spectrum applied to all potential data, along with the basement relief and 3-D view map to determine the basement depth, ranging from 1170 to $4590 \mathrm{~m}$. The basement depth decreased in the West. It was found to have values within a limit of $1200 \mathrm{~m}$. On the contrary, the basement depth in the center and the East of the investigated area was sincere and valued at more than $4500 \mathrm{~m}$. Consequently, the general dip of the basement rocks, from shallow to deep, is from the West to the center and the East.

The primary aquifer in the area under investigation, the Malhah Formation belonging to the Nubian aquifer, primarily consists of sandstone with shale and claystone intercalation. This formation, which was identified from (Al-Temid-2 borehole), is the $8^{\text {th }}$ geoelecrtical unit with a resistivity value ranging between 22 and $214 \Omega . m$. Functional similarities were found among the results obtained from VES stations' interpretation and the borehole results, the depth to the aquifer in VES No. $7=820 \mathrm{~m}$, while the depth to the aquifer in Al-Temid-2 well $=790 \mathrm{~m}$.

Meanwhile, the fourth geoelectrical unit has lower resistivity values, especially at VES stations - 4 and 9 due to dissolving the Calcium-containing formation, which raised water salinity. The fifth geoelectrical unit also has a lower resistivity value at VES-5 due to an increase in shale content, besides the sixth geoelectrical unit has a wide resistivity range due to shale content; also, the seventh geoelectrical unit at VES stations - 5, 6, and 7 is relatively low due to the high content of shale, and finally at the last one. This enormous change in the aquifer resistivity may be attributed to several factors: the aquifer's salinity, the aquifer layer's compression, and some shale intercalations.

The chemical water analysis of Al-Temid-2 water samples illustrates that the TDS value of the Lower Cretaceous aquifer was 1647 ppm. In regards to the uppermost part of the aquifer layer, it was found at a depth varying from 598 to $1106 \mathrm{~m}$. The combination of the depth to the uppermost part of the Nubian aquifer, the depth of the basement relief map revealed that the aquifer thickness varied from 430 to $3750 \mathrm{~m}$.

\section{CONCLUSION}

The results obtained from the interpretation of the integrated geophysical measurements indicate that the area of study is affected by several faults trending NorthEast-SouthWest, equivalent to the Aqaba Gulf trend, and NorthWest-SouthEast, equivalent to the Suez Gulf trend. The fault connected to the Nubian aquifer and extend upward can be considered a pass way for water migration into the shallow layer. The basement depth ranges between 1170 and $4590 \mathrm{~m}$. The investigated area contains the Nubian aquifer at depths ranging between 598 and $1106 \mathrm{~m}$, the thickness of the aquifer varies from 430 to $3750 \mathrm{~m}$, and resistivity ranges from 22 to $214 \Omega$.m. The quality of groundwater is freshwater, where the salinity is $1647 \mathrm{ppm}$. The study proposed that the site locations of VES stations 8, 10,12,17, and 18 can be considered the most suitable regions for further drilling of water wells.

\section{REFERENCES}

Ahmed, M., Sauck, W., Sultan, M., Yan, E., Soliman, F. and Rashed, M.: 2014, Geophysical constraints on the hydrogeologic and structural settings of the Gulf of Suez rift-related basins: case study from the El Qaa Plain, Sinai, Egypt. Surv Geophys, 35(2), 415-430. DOI: 10.1007/s10712-013-9259-6

Araffa, S.A.S.: 2013, Delineation of groundwater aquifer and subsurface structures on North Cairo, Egypt, using an integrated interpretation of magnetic, gravity and geoelectrical data. Int. J. Geophys., 192, 1, 94-112. DOI: $10.1093 / \mathrm{gji} / \mathrm{ggs} 008$

Araffa, S.A.S., El Shayeb, H.M., Abu Hashesh, M.F. and Hassan, N.M.: 2015, Delineating subsurface structures and assessment of groundwater aquifer using integrated geophysical interpretation at the central part of Sinai, Egypt. Arab. J. Geosci., 8, 7993-8007. DOI: $10.1007 / \mathrm{s} 12517-015-1824-5$

Bartov, Y., Lewy, Z., Steinity, G. and Zak, I.: 1980, Mesozoic and Tertiary stratigraphy, Paleogeography and structural history Gabel Arifen Naqa area, Eastern Sinai. Isr. J. Earth Sci., 29, 114-139.

Ben-Menahem, A. and Aboodi, E: 1971, Tectonic patterns in the northern Red Sea region. J. Geophys. Res., 76, 11, 2674-2689. DOI: 10.1029/JB076i011p02674

El-Awadi, E.A.: 2010, Cavity detection using geophysical methods: Evaluation and applications. VDM Verlag Dr. Müller, $152 \mathrm{pp}$.

El-Badrawy, H.T., El-Awady, M. and Soliman, M.R.: 2003, Seismo-tectonic structures as deduced from the geophysical interpretation of aeromagnetic data of the Central part of Sinai, Egypt. 6th International Conference on the M. E. A. S. T. Fac. Sci., Ain Shams University, Cairo.

El-Hinnawi, E.M. and Samy, Y.: 1995, Textural and mineralogical characteristics of coastal sediments along the Gulf of Aqaba, Sinai. Abstract, 4th Conference on Geology of Sinai for development, Ismailia.

Oasis Montaj: 2015, Geosoft mapping and processing systems. Geosoft Inc., Suite 500, Richmond St. West Toronto, ON, Canada N5UIV6.40

Ghoubachi, S.Y.: 2013, Contribution to the hydrogeology of the Lower Cretaceous aquifer in the east Central Sinai, Egypt. J. King Saud Univ. Sci., 25, 2, 91-105. DOI: $10.1016 /$ j.jksus.2010.05.009

GM-SYS 3D: 2015, Gravity and magnetic modeling, version 6.4.2 (HJ). Geosoft Inc., 207 Queens Quay West, Suite 810, Toronto, ON, Canada M5J1A7

IPI2WIN-1D Program: 2003, Programs set for 1-D VES data interpretation, Department of Geophysics, Geological Faculty, Moscow State University, Moscow, Russia. 
JICA: 1992, North Sinai groundwater resources study in the Arab Republic of Egypt, Final report. Ministry of Public Works and Water Resources, Cairo, Egypt, 3 Parts, 392 pp.

Mckenzie, D.P., Davies, D. and Molnar, P.: 1970, Plate tectonics of the Red Sea and East Africa. Nature, 226, 5242, 243-248. DOI: 10.1038/226243a0

Nettleton, L.L.: 1976, Gravity and magnetic in oil prospecting. McGraw - Hill Book Inc., New York, $322 \mathrm{pp}$.

Parker, R.L.: 1972, The rapid calculation of potential anomalies. Geophys. J. R. astr. Soc., 31, 4, 447-455. DOI. 10.1111/j.1365-246X.1973.tb06513.x

Reid, A.B., Allsop, J.M., Granser, H., Millet, A.J. and Somerton, I.W.: 1990, Magnetic interpretation in three dimensions using Euler deconvolution. Geophysics, 55, 80-91. DOI: 10.1190/1.1442774

RIGW: 2017, Central Sinai groundwater resources study in the ARE. Final report. Water Administration, Engineering Authority of the Armed Forces, Ministry of Defense, Cairo, Egypt.

Shata, A.: 1956, Structural development of the Sinai Peninsula, Egypt. Bull. Inst. Desert Egypt, 6, 2, 117157.

Spector, A. and Grant, F.S.: 1970, Statistical models for interpreting aeromagnetic data. Geophysics, 35, 2, 293-302. DOI: ;10.1190/1.1440092

Steinitz, G., Bartove, Y. and Hunziker, J.C.: 1978, K/Ar age determinations of some Miocene - Pliocene basalts in Israel: their significance to the tectonics of the rift valley. Geol. Mag. 115, 5, 329-340. DOI: $10.1017 / \mathrm{S} 0016756800037341$

Sultan, M., Ahmed, M., Sauk, W., Soliman, F., Rashed, M. and Yan, E.: 2013, Geophysical constraints on the hydrogeologic and structural settings of the Gulf of Suez Rift-related basins: a case study from the El Qaa plain, Sinai, Egypt. Surv. Geophys. 35, 415-430.
Sultan, S.A., Mekhemer, H.M. and Santos, F.A.M.: 2009, Groundwater exploration and evaluation using geophysical interpretation (case study: Al Qantara East, North Western Sinai, Egypt). Arab. J. Geosci., 2, 199-211.

Thompson, D.T.: 1982, EULDPH: a new technique for making computer-assisted depth estimates from magnetic data. Geophysics, 47, 1, 31-37. DOI: $10.1190 / 1.1441278$

Ugalde, H. and Morris, W.A.: 2010, Cluster analysis of Euler deconvolution solutions: new filtering techniques and geologic strike determination. Geophysics, 75, 3, L61-L70. DOI: $10.1190 / 1.3429997$

UNESCO Cairo Office: 2005, Geologic Map of Sinai, Egypt, Scale 1:500,000. Project for the Capacity Building of the Egyptian Geological Survey and Mining Authority, and the NARSS in Cooperation with UNDP and UNSECO, Geological Survey of Egypt.

Verduzco, B., Fairhead, J.D., Green, C.M. and MacKenzie, C.: 2004, New insights into magnetic derivatives for structural mapping. Lead. Edge, 23, 116-119. DOI: $10.1190 / 1.1651454$

Zhou, W., Nan, Z. and Li, J.: 2016, Self-constrained Euler deconvolution using potential field data of different altitudes. Pure Appl. Geophys, 173, 6, 2073-2085. DOI: $10.1007 / \mathrm{s} 00024-016-1254-7$ 